\title{
A biodegradable device for the controlled release of Piper nigrum (Piperaceae) standardized extract to control Aedes aegypti (Diptera, Culicidae) larvae
}

\author{
Kauê Muller Custódio ${ }^{[1]}$, Joice Guilherme de Oliveira ${ }^{[2]}$, Diego Moterle ${ }^{[1]}$, \\ Karine Modolon Zepon ${ }^{[1]}$, Josiane Somariva Prophiro ${ }^{[2]}$ and Luiz Alberto Kanis ${ }^{[1]}$
}

[1]. Grupo de Pesquisa em Tecnologia Farmacêutica, Programa de Pós Graduação em Ciências da Saúde, Universidade do Sul de Santa Catarina, Tubarão, Santa Catarina, Brasil. [2]. Grupo de Pesquisa em Imunoparasitologia, Programa de Pós Graduação em Ciências da Saúde, Universidade do Sul de Santa Catarina, Tubarão, Santa Catarina, Brasil.

\begin{abstract}
Introduction: The significant increase in dengue, Zika, and chikungunya and the resistance of the Aedes aegypti mosquito to major insecticides emphasize the importance of studying alternatives to control this vector. The aim of this study was to develop a controlled-release device containing Piper nigrum extract and to study its larvicidal activity against Aedes aegypti. Methods: Piper nigrum extract was produced by maceration, standardized in piperine, and incorporated into cotton threads, which were inserted into hydrogel cylinders manufactured by the extrusion of carrageenan and carob. The piperine content of the extract and thread reservoirs was quantified by chromatography. The release profile from the device was assessed in aqueous medium and the larvicidal and residual activities of the standardized extract as well as of the controlled-release device were examined in Aedes aegypti larvae. Results: The standardized extract contained $580 \mathrm{mg} / \mathrm{g}$ of piperine and an $\mathrm{LC}_{50}$ value of 5.35ppm (24h) and the 3 $\mathrm{cm}$ thread reservoirs contained $13.83 \pm 1.81 \mathrm{mg}$ of piperine. The device showed zero-order release of piperine for 16 days. The P. nigrum extract (25ppm) showed maximum residual larvicidal activity for 10 days, decreasing progressively thereafter. The device had a residual larvicidal activity for up to 37 days. Conclusions: The device provided controlled release of Piper nigrum extract with residual activity for 37 days. The device is easy to manufacture and may represent an effective alternative for the control of Aedes aegypti larvae in small water containers.
\end{abstract}

Keywords: Aedes aegypti. Larvicide. Controlled release. Piperine. Residual activity.

\section{INTRODUCTION}

Aedes aegypti (Diptera: Culicidae) female mosquitoes are among the major vectors of diseases such as chikungunya and yellow fever, and are primarily responsible for the transmission of dengue virus and, more recently, the Zika virus ${ }^{(1)(2)(3)}$. Currently, there is no specific treatment or effective vaccine to prevent dengue, Zika, or chikungunya infection ${ }^{(3)}$. Thus, controlling the vector remains the primary method of controlling the disease, and can be done by eliminating mosquito breeding sites in addition to insecticide application to larval and adult forms ${ }^{(4)}$. However, the widespread use of pyrethroid and organophosphorus compounds has promoted the selection of A. aegypti resistant populations in many countries and has rendered these synthetic substances ineffective $e^{(5)(6)(7)(8)}$.

Corresponding author: Dr. Luiz Alberto Kanis.

e-mail: luizalbertokanis@gmail.com

Received 25 August 2016

Accepted 14 October 2016
This situation has highlighted the need for developing new alternatives to control the disease, especially biodegradable alternatives that may slow or prevent the development of resistance. Several studies have indicated that plants and plant-derived chemical compounds can be used as alternatives to synthetic insecticides ${ }^{(9)(10)}$. Among the plants with potential larvicidal activity, the Piper genus is of note, mainly due to its piperine content and that of its derivatives ${ }^{(11)(12)(13)(14)(15)(16)}$.

Several studies have shown that Piper nigrum extract has larvicidal activity against A. aegypti ${ }^{(15)(17)(18)(19)(20)(21)}$. However, because of its vegetable origin, it has low residual activity due to the degradation of piperine, the main active component of P. nigrum $^{(22)}$.

The incorporation of insecticides and pesticides into polymer matrices is a strategy to reduce the degradation rate in addition to delaying the release of the active substance into the environment, thus providing increased residual activity ${ }^{(23)(24)}$. Polysaccharides are polymers with potential for the development of controlledrelease systems ${ }^{(25)}$. They are abundant, biodegradable natural polymers that can be used to produce micro- or nanocapsules and 
hydrogels with the aim of reducing pesticide use and toxicity, thus protecting both the environment and human health ${ }^{(25)}$. Among the main polysaccharides, carrageenan is highlighted for its biodegradability and capability to form hydrogels ${ }^{(26)(27)}$. The aim of this study was to develop a controlled-release device of biodegradable polysaccharide-based formulation and with a cotton thread containing standardized extract of $P$. nigrum, to be used in small water storage containers to control the A. aegypti larvae.

\section{METHODS}

\section{Aedes aegypti larvae}

Rockefeller strains of $A$. aegypti were continuously maintained in a laboratory under a $14 \mathrm{~h}$ light $/ 10 \mathrm{~h}$ dark photoperiod. Larvae were raised on powdered pet food (Purina ${ }^{\circledR}$ Cat Chow ${ }^{\circledR}, 0.2 \mathrm{~g} / 100 \mathrm{~mL}$, three times per week). Adult males and females were continuously provided with a $5 \%$ honey solution, while females were blood-fed on BALB/c mice, twice per week, in order to obtain eggs for colony development. All bioassays were performed at $25^{\circ} \mathrm{C}$ and $80 \%( \pm 10 \%)$ relative humidity in an ELETROlab ${ }^{\circledR} 132 \mathrm{FC}$ incubator.

\section{Piper nigrum extract}

Dried and ground $(<500 \mu \mathrm{m}) P$. nigrum grains underwent dynamic maceration for $48 \mathrm{~h}$ in $95 \%$ ethyl alcohol at a plant-tosolvent ratio of 1:20. The solvent was evaporated at $50^{\circ} \mathrm{C}$ under reduced pressure using a Heidolph VV2200 rotary evaporator. The extract obtained was named Piper nigrum extract (PnE ) and was stored at $5^{\circ} \mathrm{C}$, protected from light.

\section{Piper nigrum extract standardization in piperine}

The piperine content of PnE was determined using high-performance liquid chromatography (HPLC) ${ }^{(28)}$. The chromatographic system used was a Shimadzu A10 apparatus and ultraviolet-visible (UV-VIS) detector, mobile phase acetonitrile (Vetec SA, Brasil:1\% acetic acid (Vetec SA, Brasil): water, Phenomenex Luna C18 column $(150 \mathrm{~mm} \times 4.6 \mathrm{~mm} \times \mathrm{x} 5 \mu \mathrm{m}), 343 \mathrm{~nm}$ wavelength detection, $30^{\circ} \mathrm{C}$ oven temperature, $1 \mathrm{ml} / \mathrm{min}$ flow, and $20 \mu \mathrm{L}$ injection volume. A calibration curve with standard piperine solutions (SigmaAldrich, 97\%) was used for quantification and prepared in methanol at concentrations of $4-6 \mu \mathrm{g} / \mathrm{mL}$.

\section{Lethal concentration $\left(\mathrm{LC}_{50}\right)$ determination}

A stock PnE solution of 200ppm was prepared in water containing $0.2 \mathrm{mg} / \mathrm{mL}$ Polysorbate 80 (Synth SA, Brasil). The solution was diluted in water to concentrations of $1-40 \mathrm{ppm}$. $A$. aegypti larvae $(\mathrm{n}=25)$ were added to $50 \mathrm{~mL}$ of PnE solution and maintained at $25^{\circ} \mathrm{C}$ and $80 \%( \pm 10 \%)$ relative humidity in an acclimatized chamber. Larval mortality was observed after $24 \mathrm{~h}$ of exposure to solutions. Larvae were considered dead if they did not respond to a gentle $\operatorname{prod}^{(29)}$. The experiment was conducted in triplicate using water and the highest concentration of Polysorbate 80 as a control.

The lethal concentrations $\left(\mathrm{LC}_{50}\right.$ and $\left.\mathrm{LC}_{99}\right)$ were interpolated by probit analysis using GraphPad PRISM software (GraphPad
Software 1995, San Diego, CA, USA) and were reported as means \pm standard deviation (SD) from three experiments.

\section{Manufacture of controlled-release device}

The controlled-release device (CRD) was composed of a cotton thread impregnated with $P$. nigrum extract, standardized in piperine (active), and coated with a hydrogel cylinder to control the release (Figure 1).

Hydrogel cylinder manufacturing: a solution was prepared containing carrageenan CG 130 (CP Kelko,USA): locust bean gum LBG 246 (CP Kelko,USA) : KCl (Synth SA, Brasil) in water at a ratio of $1.25: 1.0: 0.2 \%$. The solution was heated to $60^{\circ} \mathrm{C}$ and extruded using a cold piping system to obtain hydrogel cylinders.

Production of P. nigrum extract reservoir: cotton threads (5mm diameter, $3 \mathrm{~cm}$ length) were immersed for 15 minutes in a solution containing 5\% polyethylene glycol (PEG) 4000 (Synth SA, Brasil)nd $200 \mathrm{mg} / \mathrm{mL} \mathrm{PnE} \mathrm{(previously} \mathrm{solubilized} \mathrm{in} 95^{\circ} \mathrm{GL}$ ethanol (Vetec SA, Brasil). Next, the threads were removed and dried at room temperature $\left(22 \pm 4{ }^{\circ} \mathrm{C}\right)$ for $1.5 \mathrm{~h}$ before insertion into the hydrogel cylinders to produce the CRD.

Determination of piperine content of the reservoir: the impregnated cotton threads were maintained under ultrasonic agitation in a volumetric flask containing $50 \mathrm{~mL}$ of ethanol for 30 minutes. The extract solution was diluted 10 fold and piperine content was determined by the chromatographic method described above. Analyses were performed in triplicate.

\section{Piperine release mechanism}

Devices measuring $3 \mathrm{~cm}$ in length were packed in amber glass bottles containing $200 \mathrm{~mL}$ of water and maintained under constant stirring at temperatures ranging from $25-30^{\circ} \mathrm{C}$. Samples of solution were removed at predetermined intervals and the amount of piperine released was determined using the chromatographic method described above.

\section{Residual effect of Piper nigrum extract and controlled- release device}

Residual larvicidal activity of PnE: a PnE solution was prepared at a concentration of $25 \mathrm{ppm}$ (8-fold higher than the 24-h $\left.\mathrm{LC}_{50}\right)$. Sample solutions $(200 \mathrm{~mL})$ were transferred to beakers containing $50 \mathrm{~A}$. aegypti larvae. Larval mortality was assessed after $24 \mathrm{~h}$, with larvae not responding to gentle

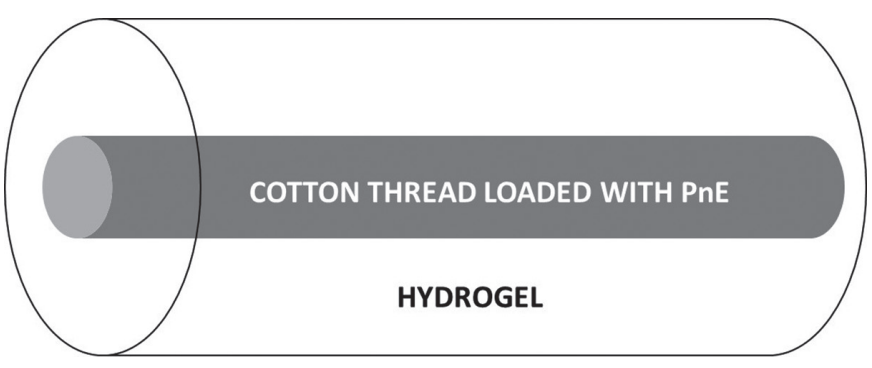

FIGURE 1. Structure of the controlled release device. PnE: Piper nigrum extract. 
prodding considered dead ${ }^{(29)}$. Dead and surviving larvae were discarded and replaced with 50 new specimens, after filtration of the solutions. This procedure was repeated until no further dead larvae were observed. The same procedure was followed for the control group.

Residual larvicidal activity of the CRD: CRD samples were added to $200 \mathrm{~mL}$ of water along with $50 \mathrm{~A}$. aegypti larvae in each replicate. Mortality was assessed every $24 \mathrm{~h}$, and the solution was filtered before adding new larvae whenever a mortality rate above $80 \%$ was achieved. The water in the reservoir was completely renewed on day 7,12 , and 17 to determine the effect of water renewal frequency on larval mortality.

\section{Statistical analyses}

The results were presented as mean and SD and were evaluated by analysis of variance (ANOVA) followed by Tukey's test, using OriginPro 7.0 software and a significance level of 0.05 .

\section{RESULTS}

The results of PnE larvicidal activity $\left(\mathrm{LC}_{50}\right)$ and piperine concentration are shown in Table 1.

Piper nigrum extract showed piperine content close to $60 \%$ of its total mass, which demonstrates that the extract is rich in this chemical substance. The $\mathrm{LC}_{50}$ values for PnE showed a gradual decrease in larvicide exposure over time, but significant differences were observed only between the 24-h and 48-h time intervals. The results indicate that the PnE larvicidal activity assigned to piperine at $\mathrm{LC}_{50}$ was $1.6 \mathrm{ppm}$ within $48 \mathrm{~h}$, i.e., $60 \%$ of the value determined for PnE. Figure 2 shows images of the CRD top and side view.

The hydrogel extrusion process produced homogenous cylinders with walls $5.0 \pm 0.3 \mathrm{~mm}$ thick. Reservoir threads measuring $3 \mathrm{~cm}$ in length had piperine content of $13.83 \pm 1.81 \mathrm{mg}$ and were easily introduced into the cylinder to form the CRD.

Piper nigrum extract release (mean and SD) from the CRD was determined in an aqueous medium at a temperature range of $25-30^{\circ} \mathrm{C}$ (Figure 3).

Piperine release from the CRD showed linear kinetics $(\mathrm{r}=0.9964)$ for 16 days, according to Equation 1, where $P R$ ( $\mathrm{mg}$ ) is the amount of piperine released and $\mathrm{t}$ is time (in days). After 16 days, a decrease in PR concentration of the aqueous medium was observed. The highest concentration of piperine released into the medium was $2.7 \pm 1.79 \mathrm{mg}$, achieved on day 16 .

$$
P R(\mathrm{mg})=0.0341+0.173 * t(\text { days }) \quad \text { (Equation } 1)
$$

Figure 4 shows the results of the residual activity against A. aegypti larvae produced by the CRD containing PnE.

Piper nigrum extract at a concentration of $25 \mathrm{ppm}$ (8-fold higher concentration than $\mathrm{LC}_{50}$ at $48 \mathrm{~h}$ ) achieved $100 \%$ larval mortality during the first 10 days of the study period, after which larvicidal activity declined until becoming ineffective on day 31 .

The CRD showed increased larvicidal activity for the first 4 days, reaching $80 \%$ mortality, which was maintained until day 7. The reservoir water was then renewed and the larvae replaced, initiating a new phase of progressive release
TABLE 1

Piperine content and $\mathrm{LC}_{50}$ values for Piper nigrum extract at 24,48 , and $72 \mathrm{~h}$ of exposure.

Piperine (mg/g)

\begin{tabular}{ccc}
\multicolumn{3}{c}{$\mathrm{LC}_{50}(\mathrm{ppm}$ of extract $)$} \\
\hline $24 \mathrm{~h}$ & $48 \mathrm{~h}$ & $72 \mathrm{~h}$
\end{tabular}

$580 \pm 1.9 \quad 5.3 \pm 0.42^{\mathrm{a}} \quad 3.2 \pm 0.37^{\mathrm{b}} \quad 3.1 \pm 0.36^{\mathrm{b}}$

$\mathbf{L C}_{50}$ : lethal concentration required to kill $50 \%$ of larvae. ${ }^{\mathbf{a}, \mathbf{b}}$ : Means sharing the same superscript letter are not significantly different from each other $(\mathrm{p}<0.05)$.
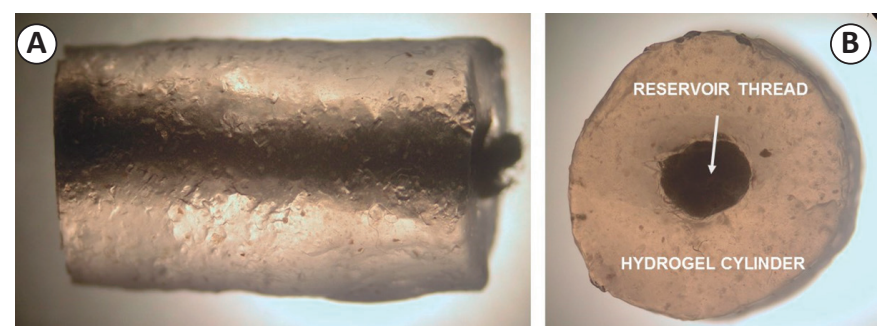

FIGURE 2. Polymeric devices containing Piper nigrum extract. A. Side view ( $1 \mathrm{~cm}$ length). B. Top view.

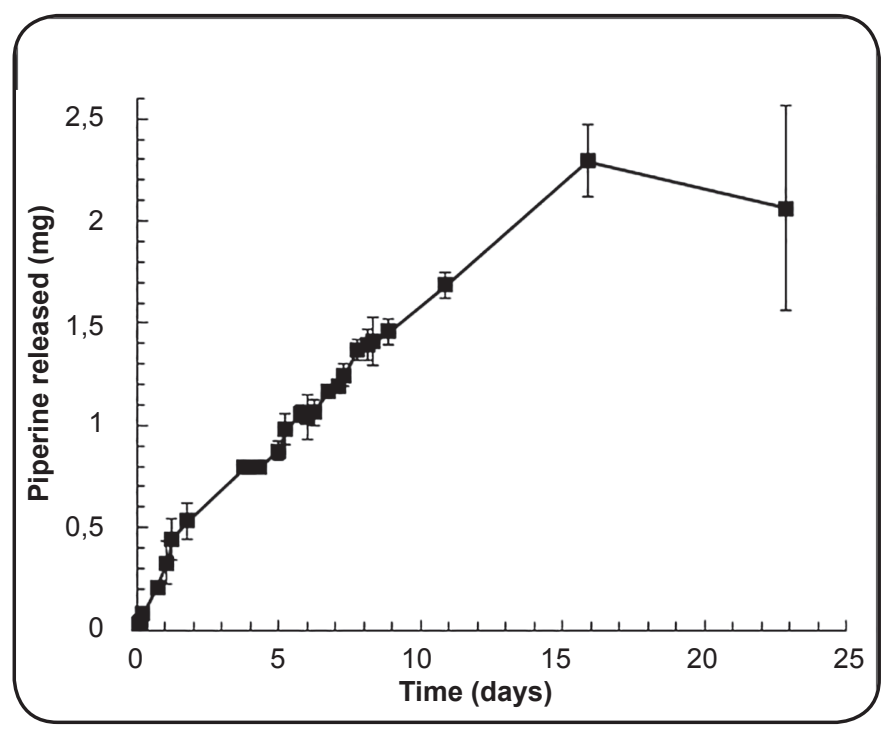

FIGURE 3. Concentration of piperine released (mg) in an aqueous medium from the controlled-release device over time. Vertical bars = standard deviation.

of piperine into the aqueous medium. Larvicidal activity above $80 \%$ was again achieved, on day 12 , when water renewal and larvae replacement were repeated. Similar results were obtained on day 17, followed by the same procedure. From this point onwards, water renewal was not performed and larvae were replaced only when larvicidal activity was greater than $80 \%$. The residual activity was maintained until day 30 , when a reduction in PnE lethality required a longer exposure time to reach $80 \%$. The residual activity ceased on day 37 . 


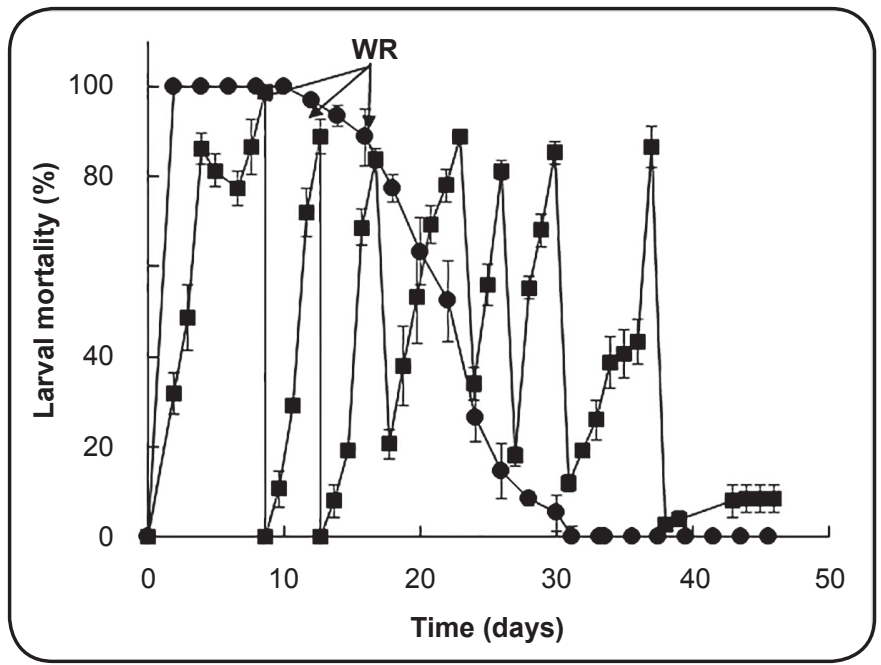

FIGURE 4. Residual activity of Piper nigrum extract at a concentration of 25 ppm (•) and the controlled release device ( $\bullet$ ). WR: reservoir water renewal. Vertical bars $=$ standard deviation .

\section{DISCUSSION}

Piper nigrum seeds are known for their high piperine concentration and insecticidal activity against various species of insects. Several studies have demonstrated that this insecticidal activity is related to the presence of piperine and its derivatives ${ }^{(19)(20)(21)(22)}$. The development of any device from natural products with a potential insecticidal application, such as $P$. nigrum, requires a standardized extract of the main active component to be obtained to ensure both effectiveness and safety ${ }^{(30)}$. PnE showed a piperine concentration above $60 \%$ of the total extracted substances, indicating that the extraction process was sufficiently efficient and selective for large-scale production. PnE showed an $\mathrm{LC}_{50}$ less than $5 \mathrm{ppm}$, indicating potent larvicidal activity. Several studies have evaluated the larvicidal activity of $P$. nigrum extract in which $\mathrm{LC}_{50}$ values ranged from 5-90ppm, higher than those produced by the PnE in the present study. This difference was likely associated with differences in the methods used to obtain the extract ${ }^{(21)(31)(32)}$. The lack of standardization hampers the comparison between different piperine content rates; however, Ik and colleagues have found $\mathrm{LC}_{50}$ values of $3.21 \mathrm{ppm}$ for isolated piperine ${ }^{(33)}$, which is similar to the LC50 determined for PnE containing only $60 \%$ piperine. These findings indicate that $\mathrm{PnE}$ activity cannot be attributed solely to piperine but also to other isobutylamide compounds found in this species such as retrofractamide $\mathrm{A}$ and pellitorine, piperine derivatives that have shown $\mathrm{LC}_{50}$ values of $0.028 \mathrm{ppm}$ and 0.86 , respectively ${ }^{(34)}$.

Piper nigrum extract was successfully incorporated into cotton thread reservoirs at $13 \mathrm{mg}$ of piperine per $3 \mathrm{~cm}$, on average. This amount of PnE, when fully released into $200 \mathrm{~mL}$ of water, produced a piperine concentration exceeding 70ppm, a 20 fold higher value than the $\mathrm{LC}_{50}$ values determined for $\mathrm{PnE}(3.2 \mathrm{ppm})$ at $48 \mathrm{~h}$ and higher than those determined for $P$. nigrum extracts in other studies. However, quick release to the medium was not the objective, as this would produce a highly toxic concentration, unnecessary for effectiveness, and facilitate piperine degradation ${ }^{(35)}$, thus promoting a rapid loss of biological activity.

Piper nigrum extract incorporation into the CRD, however, produced a prolonged release of piperine into the aqueous medium with zero-order kinetics for the first 16 days of the study period. A release behavior that follows zero-order kinetics can provide an active agent release rate proportional to the length of time ${ }^{(36)}$. This behavior is the most common objective of any CRD, as it allows prediction of the amount of active agents released at a given time interval as well as a determination of whether the amount is sufficient to promote the desired effect. According to Equation 1, the constant rate of piperine release during the linear phase was $0.207 \mathrm{mg} /$ day, providing a concentration of $2.06 \mathrm{ppm}$ in $48 \mathrm{~h}$ in $200 \mathrm{~mL}$ of water (the volume in which the larvae were deposited). If all components of the extract were released in a similar manner, 2.06ppm of piperine would correspond to 3.42ppm of $\mathrm{PnE}(\mathrm{PnE}$ contains as much as $60 \%$ piperine), meaning that, within $48 \mathrm{~h}$, the concentration released was higher than the quantified $\mathrm{LD}_{50}$ for $\mathrm{PnE}(3.1 \mathrm{ppm})$. The reduction in piperine concentration observed in Figure 3 from day 16 onwards can only be explained by its degradation in the aqueous medium, given that the concentration released is cumulative and that concentration stabilization would be expected, indicating the end of the release process. Despite having good chemical stability in aqueous medium, in vitro studies have shown that piperine undergoes hydrolytic degradation under physiological medium or when exposed to light ${ }^{(37)}$.

Rapid biodegradation of plant-derived substances is advantageous because it leads to less environmental contamination, although it also has disadvantages because it reduces residual activity and creates the need for repeated

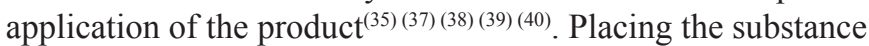
in a CRD may therefore increase the duration of residual activity and protect against degradation ${ }^{(41)}$.

The PnE residual larvicidal activity observed was similar to that found in other studies with Piperaceae extracts in which maximal activity was maintained for a maximum of 15 days and was concentration dependent ${ }^{(12)(42)}$. After this period, activity decreased, which was attributed to degradation of the active ingredients ${ }^{(19)}$. However, it is worth noting that $\mathrm{PnE}$ has a higher duration of residual activity compared with other natural products such as copaiba oil and andiroba, a characteristic of interest for the incorporation into $\mathrm{CRD}^{(43)}$.

The maximum duration of CRD residual activity was 37 days; however, whenever larvae were replaced, a time interval was required to again achieve larvicidal activity above $80 \%$. This behavior can be explained by differences in the concentration of active component available in the aqueous medium to promote the larvicidal activity. In the case of PnE, a concentration of $25 \mathrm{ppm}$ was constantly available to promote this effect, whereas for the CRD, approximately $3.4 \mathrm{ppm}$ of PnE was released every $48 \mathrm{~h}$. This characteristic is expected from the CRD as its function is to promote the gradual release of active component into the aqueous medium, sufficient to promote activity, but at the lowest concentration required, thus reducing degradation of the active component and toxicity to the environment. 
Most studies assessing larvicidal activity against $A$. aegypti examine only the $\mathrm{LC}_{50}$ values; few determine the residual activity of insecticides and even fewer take into account the dynamics of water renewal that occurs naturally in domestic reservoirs. Previous studies have indicated that water renewal can have a negative influence on the larvicide residual activity used in vector control programs ${ }^{(44)}$.

Water renewal during CRD evaluation was performed three times between day 7 and 17 . This process caused the removal of the active component already released, requiring the device to release additional component to ensure that larvicidal activity was maintained. In this manner, the CRD was capable of achieving larvicidal activity after all instances of water renewal, which was essential to achieve the proposed objectives of the device. In contrast, there was a sudden loss of activity at day 37. Data fitting to Equation 1 revealed that only $6.4 \mathrm{mg}$ of piperine was released within that time interval, corresponding to $50 \%$ of the total amount incorporated into the device (13mg). In most CRDs, only a portion of the active agents is released, due to interactions between the polymeric materials and active substance retention ${ }^{(45)}$. Thus, the reduced activity may be attributed to degradation of piperine and the retention of the active components in the polymer matrix.

In conclusion, the findings from this study indicate that it is possible to produce a standardized extract from $P$. nigrum, rich in piperine, with high larvicidal activity against $A$. aegypti. The incorporation of this extract into a CRD composed entirely of biodegradable and non-toxic materials, carrageenan polysaccharide and locust bean gum, provided the controlled release of piperine with residual activity for 37 days under water-renewal conditions. Furthermore, it is of note that the device described is easy to manufacture using standard polymer extrusion systems.

\section{Conflict of Interest}

The authors declare that there is no conflict of interest.

\section{Financial Support}

This study was financially supported by grants from the Brazilian National Council for Scientific and Technological Development [Conselho Nacional de Desenvolvimento Científico e Tecnológico (CNPq)], the Institutional Scientific Initiation Scholarship Program [Programa Institucional de Bolsas de Iniciação Científica (PIBIC)], and the University of Southern Santa Catarina [Universidade do Sul de Santa Catarina (UNISUL)], Innovation and Entrepreneurship Agency of Unisul [(Agência de Gestão, desenvolvimento científico, tecnologia e inovação da Unisul (AGETEC)].

\section{REFERENCES}

1. Benelli G, Mehlhorn H. Declining malaria, rising dengue and Zika virus: insights for mosquito vector control. Parasitol Res 2016; 115:1747-1754.

2. Ribeiro GS, Kitron U. Zika virus pandemic: a human and public health crisis. Rev Soc Bras Med Trop 2016; 49:1-3.

3. Marcondes BC, Ximenes MFFM. Zika virus in Brazil and the danger of infestation by Aedes (Stegomyia) mosquitoes. Rev Soc Bras Med Trop 2016; 49:4-10.
4. Hermann LL, Gupta SB, Manoff SB, Kalayanarooj S, Gibbons RV, Coller BAG. Advances in the understanding, management, and prevention of dengue. J Clin Virol 2015; 64:153-159.

5. Lima EP, Oliveira Filho AM, Lima JWO, Ramos Júnior AN, Cavalcanti LPG, Pontes RJS. Resistência do Aedes aegypti ao temefós em Municípios do Estado do Ceará. Rev Soc Bras Med Trop 2006; 39:259-263.

6. World Health Organization (WHO). Dengue guidelines for diagnosis, treatment, prevention and control. New edition. Geneva: World Health Organization; 2009. p. 147.

7. Prophiro JS, Silva OS, Luna JED, Piccoli CF, Kanis LA, Silva MAN. Aedes aegypti and Aedes albopictus (Diptera: Culicidae): coexistence and susceptibility to temephos, in municipalities with occurrence of dengue and differentiated characteristics of urbanization. Rev Soc Bras Med Trop 2011; 44:300-305.

8. Karunaratne SHPP, Weeraratne TC, Perera MDB, Surendran SN. Insecticide resistance and, efficacy of space spraying and larviciding in the control of dengue vectors Aedes aegypti and Aedes albopictus in Sri Lanka. Pestic Biochem Physiol 2013; 107:98-105.

9. Reegan AD, Gandhi MR, Paulraj MG, Balakrishna K, Ignacimuthu S. Effect of niloticin, a protolimonoid isolated from Limonia acidissima L. (Rutaceae) on the immature stages of dengue vector Aedes aegypti L. (Diptera: Culicidae). Acta Trop 2014; 139:67-76.

10. Rajeswary M, Govindarajan M. Adulticidal properties of Pithecellobium dulce (Roxb.) Benth. (Family: Fabaceae) against dengue vector, Aedes aegypti (Linn.) (Diptera: Culicidae). Asian Pac J Trop Dis 2014; 4 (suppl 1):S449-S452.

11. Chaithong U, Choochote W, Kamsuk K, Jitpakdi A, Tippawangkosol P, Chaiyasit D, et al. Larvicidal effect of pepper plants on Aedes aegypti (L.) (Diptera: Culicidae). J Vector Ecol 2006; 31:138-144.

12. Kanis LA, Rabelo BD, Moterle D, Machado Nogaretti R, Nunes T, Santos da Silva O, et al. Standardized extract of Piper ovatum (Piperaceae) to control Aedes aegypti larvae (Diptera: Culicidae). Ind Crops Prod 2013; 50:816-820.

13. Morais SM, Facundo VA, Bertini LM, Cavalcanti ESB, AnjosJúnior JF, Ferreira SA, et al. Chemical composition and larvicidal activity aof essential oils from Piper species. Biochem Syst Ecol 2007; 35:670-675.

14. da Silva MFR, Bezerra-Silva PC, de Lira CS, de Lima Albuquerque BN, Agra Neto AC, Pontual EV, et al. Composition and biological activities of the essential oil of Piper corcovadensis (Miq.) C. DC (Piperaceae). Exp Parasitol 2016; 165:64-70.

15. Samuel M, Oliver SV, Coetzee M, Brooke BD. The larvicidal effects of black pepper (Piper nigrum L.) and piperine against insecticide resistant and susceptible strains of Anopheles malaria vector mosquitoes. Parasit Vectors 2016; 9:238.

16. Santana AI, Vila R, Cañigueral S, Gupta MP. Chemical composition and biological activity of essential oils from different species of Piper from Panama. Planta Med 2016; 82:986-991.

17. Siddiqui BS, Gulzar T, Begum S, Afshan F. Piptigrine, a new insecticidal amides from Piper nigrum Linn. Nat Prod Res 2004; $18: 473-477$

18. Gulzar T, Uddin N, Siddiqui BS, Naqvi SNH, Begum S, Tariq RM. New constituents from the dried fruit of Piper nigrum Linn., and their larvicidal potential against the dengue vector mosquito Aedes aegypti. Phytochem Lett 2013; 6:219-2230.

19. Lija-Escaline J, Senthil-Nathan S, Thanigaivel A, Pradeepa V, Vasantha-Srinivasan P, Ponsankar A, et al. Physiological and biochemical effects of botanical extract from Piper nigrum Linn (Piperaceae) against the dengue vector Aedes aegypti Liston (Diptera: Culicidae). Parasitol Res 2015; 114:4239-4249. 
20. Santiago VS, Alvero RG, Villaseñor IM. Aedes aegypti larvicide from the ethanolic extract of Piper nigrum black peppercorns. Nat Prod Res 2015; 29:441-443.

21. Kato Simas N, Da E, Lima C, Kuster RM, Luiz C, Lage S, et al. Potential use of Piper nigrum ethanol extract against pyrethroidresistant Aedes aegypti larvae. Rev Soc Bras Med Trop 2007; 40:405-407.

22. Scott IM, Jensen HR, Philogène BJR, Arnason JT. A review of Piper spp. (Piperaceae) phytochemistry, insecticidal activity and mode of action. Phytochem Rev 2008; 7:65-75.

23. Badawy MEI, Taktak NEM, Awad OM, Elfiki SA, Abou El-Ela NE. Larvicidal activity of temephos released from new chitosan/ alginate/gelatin capsules against Culex pipiens. Int J Mosq Res 2015; 2:45-55.

24. Saleh MS, Abuzinadah OA, Al-Ghamdi KM, Alsagaf AA, Mahyoub JA. Effectiveness of slow-release tablet formulations of the IGR diflubenzuron and the bioinsecticide spinosad against Larvae of Aedes aegypti (L.). African Entomol 2013; 21:349-353.

25. Campos EVR, Oliveira JL, Fraceto LF, Singh B. Polysaccharides as safer release systems for agrochemicals. Agron Sustain Dev 2015; 35:47-66.

26. Prajapati VD, Maheriya PM, Jani GK, Solanki HK. Carrageenan: a natural seaweed polysaccharide and its applications. Carbohydr Polym 2014; 105:97-112.

27. Li L, Ni R, Shao Y, Mao S. Carrageenan and its applications in drug delivery. Carbohydr Polym 2014; 103:1-11.

28. Wood AB, Barrow ML, James DJ. Piperine determination in pepper (Piper nigrum L.) and its oleoresins - a reversed-phase highperformance liquid chromatographic method. Flavour Fragr J 1988; 3:55-64.

29. World Health Organization (WHO). Instructions for determining the susceptibility or resistance of mosquitoes larvae to insecticides. WHO/VBC/81.807. Geneva: World Health Organization; 1981. 6p. Available at: http://www.who.int/iris/handle/10665/69615.

30. Chauhan R, Dwivedi J, Siddiqui AA. Chemical Standardization and quantification of Piperin from methanolic extract of Piper nigrum by HPLC method on the basis of isolated markers. Int J Chem Sci 2008; 6:1726-1733.

31. Vasudevan K, Malarmagal R, Charulatha H, Saraswatula VL, Prabakaran K. Larvicidal effects of crude extracts of dried ripened fruits of Piper nigrum against Culex quinquefasciatus larval instars. J Vector Borne Dis 2009; 46:153-156.

32. Nath DR, Bhuyan M, Goswami S. Botanicals as mosquitolarvicides. Def Sci J 2006; 56:507-511.
33. Park IK, Lee SG, Shin SC, Park JD, Ahn YJ. Larvicidal activity of isobutylamides identified in Piper nigrum fruits against three mosquito species. J Agric Food Chem 2002; 50:1866-1870.

34. Park IK. Insecticidal activity of isobutylamides derived from Piper nigrum against adult of two mosquito species, Culex pipiens pallens and Aedes aegypti. Nat Prod Res 2012; 26:2129-2131.

35. Kotte SCB, Dubey PK, Murali PM. Identification and characterization of stress degradation products of piperine and profiling of a black pepper (Piper nigrum L.) extract using LC/QTOF-dual ESI-MS. Anal Methods 2014; 6:8022-8029.

36. Shaikh HK, Kshirsagar RV, Patil SG. Mathematical Models for Drug Release Characterization: a Review. World J Pharm Pharmacent Sci 2015; 4:324-338.

37. Singh A, Jayaraman S, Jayaram Kumar K, Rani A, Nema RK. Stability-indicating HPTLC determination of piperine in bulk drug and pharmaceutical formulations. Asian J Chem 2008; 20:60076010 .

38. Kühne S. Prospects and limits of botanical insecticides in organic farming. Agron Glas 2008; 4:377-382.

39. George DR, Finn RD, Graham KM, Sparagano OAE. Present and future potential of plant-derived products to control arthropods of veterinary and medical significance. Parasit Vectors 2014; 7:PMC3905284.

40. Jarvis AP, Johnson S, Morgan ED. Stability of the natural insecticide azadirachtin in aqueous and organic solvents. Pestic Sci 1998; 53:217-222.

41. Roy A, Singh SK., Bajpai J, Bajpai AK. Controlled pesticide release from biodegradable polymers. Cent Eur J Chem 2014; 12:453-469.

42. Benelli G, Canale A, Conti B. Eco-friendly control strategies against the Asian tiger mosquito, Aedes albopictus (Diptera: Culicidae): repellency and toxic activity of plant essential oils and extracts. Pharmacol Online 2014; 1:44-51.

43. Prophiro JS, Silva MAN, Kanis LA, Silva BM, Duque-Luna JE, Silva OS. Evaluation of time toxicity, residual effect, and growthinhibiting property of Carapa guianensis and Copaifera sp. in Aedes aegypti. Parasitol Res 2012; 110:713-719.

44. Pontes RJS, Dantas Filho FF, Alencar CHM, Regazzi ACF, Cavalcanti LP G, Ramos Jr AN, et al. Impact of water renewal on the residual effect of larvicides in the control of Aedes aegypti. Mem Inst Oswaldo Cruz 2010; 105:220-224.

45. Lin S-Y, Lee C-J, Lin Y-Y. Drug-polymer interaction affecting the mechanical properties, adhesion strength and release kinetics of piroxicam-loaded Eudragit E films plasticized with different plasticizers. J Control Release 1995; 33:375-381. 